\title{
Utilizing Standardized Patient Feedback to Facilitate Professional Behavior in Physical Therapist Students: A Pilot Study
}

\author{
Mary Anne Riopel \\ Kean University, mriopel.pt@gmail.com \\ Bini Litwin \\ Nova Southeastern University \\ Nicki Silberman \\ Hunter College \\ Alicia Fernandez-Fernandez \\ Nova Southeastern University
}

Follow this and additional works at: https://nsuworks.nova.edu/ijahsp

Part of the Higher Education Commons, and the Physical Therapy Commons

\section{Recommended Citation}

Riopel M, Litwin B, Silberman N, Fernandez-Fernandez A. Utilizing Standardized Patient Feedback to Facilitate Professional Behavior in Physical Therapist Students: A Pilot Study. The Internet Journal of Allied Health Sciences and Practice. 2018 Jan 01;16(3), Article 4.

This Manuscript is brought to you for free and open access by the College of Health Care Sciences at NSUWorks. It has been accepted for inclusion in Internet Journal of Allied Health Sciences and Practice by an authorized editor of NSUWorks. For more information, please contact nsuworks@nova.edu. 


\title{
Utilizing Standardized Patient Feedback to Facilitate Professional Behavior in Physical Therapist Students: A Pilot Study
}

\begin{abstract}
Purpose: Physical therapist (PT) students receive feedback on professional behavior performance from academic and clinical faculty members. Literature is lacking on the impact that verbal feedback from standardized patients (SPs) may have on physical therapist student learning of professional behaviors. The purpose of this pilot study was to examine the use of standardized patients' feedback as a strategy for professional behavior development. Methods: A sample of convenience identified 13 doctoral physical therapist students prior to initiation of their first full-time clinical experience. Subjects were excluded if they had prior experiences with standardized patients or had completed a full-time clinical experience. Using a randomized control design, the experimental group $(n=7)$ received standardized patient verbal feedback and written rubric assessment, whereas the comparison group $(n=6)$ received written rubric assessment alone after completing standardized patient case scenarios. Outcome measures included the Modified Standardized Patient Satisfaction Questionnaire (MSPSQ), Professional Behaviors Assessment (PBA), and Professionalism Physical Therapy Core Values Assessment (PPTCVA). Results: Data analysis included pre and post intervention comparisons of Modified Standardized Patient Satisfaction Questionnaire rubric assessment scores, Professional Behaviors Assessment scores, and Professionalism Physical Therapy Core Values Assessment scores. No statistically significant differences were found on these outcome measures, although trends for changes in performance were noted. Conclusions: Limited research exists on the impact of standardized patients' verbal feedback with the use of a standardized rubric on physical therapist student professional behavior. This pilot study did not provide significant evidence on the value of this educational strategy in development of professional behaviors in doctoral physical therapist students. Future research may be beneficial to examine differences in perceptions of professional behavior between standardized patients, students, and faculty.
\end{abstract}

\section{Author Bio(s)}

Mary Anne Riopel, PT, DPT, PhD, OCS, is an Assistant Professor in the School of Physical Therapy at Kean University. She completed her PhD in Physical Therapy with emphasis on research on the use of standardized patients for professional behavior development in physical therapist students.

Bini Litwin PT, DPT, PhD, MBA, is an Associate Professor in the Physical Therapy Department at Nova Southeastern University in Fort Lauderdale, Florida. She completed her PhD in Conflict Resolution with an emphasis on organizational behavior. Her research focuses on cardiovascular/pulmonary clinical practice, simulation strategies and cultural diversity.

Nicki Silberman, PT, DPT, PhD, is an Assistant Professor and the Director of Clinical Education at Hunter College. She is a certified trainer for the APTA's Clinical Instructor Credentialing Program. Her research interests include high fidelity human simulation and PT student preparation and performance for clinical experiences in acute care.

Alicia Fernandez-Fernandez, PT, DPT, PhD, earned her PhD in Biomedical Engineering, and is a certified neonatal therapist. She is currently an Associate Professor in the physical therapy department at Nova Southeastern University in Fort Lauderdale, FL, and her research interests encompass pediatrics, biomechanics, innovative educational approaches, and nanotechnology. 


\title{
IITAHSP \\ The Internet Joưnal of Allied Health Sciences and Practice
}

Dedicated to allied health professional practice and education

Vol. 16 No. 3 ISSN 1540-580X

\section{Utilizing Standardized Patient Feedback to Facilitate Professional Behavior in Physical Therapist Students: A Pilot Study}

\author{
Mary Anne Riopel ${ }^{1}$ \\ Bini Litwin² \\ Nicki Silberman ${ }^{3}$ \\ Alicia Fernandez-Fernandez ${ }^{2}$ \\ 1. Kean University \\ 2. Nova Southeastern University \\ 3. Hunter College
}

United States

\begin{abstract}
Purpose: Physical therapist (PT) students receive feedback on professional behavior performance from academic and clinical faculty members. Literature is lacking on the impact that verbal feedback from standardized patients (SPs) may have on physical therapist student learning of professional behaviors. The purpose of this pilot study was to examine the use of standardized patients' feedback as a strategy for professional behavior development. Methods: A sample of convenience identified 13 doctoral physical therapist students prior to initiation of their first full-time clinical experience. Subjects were excluded if they had prior experiences with standardized patients or had completed a full-time clinical experience. Using a randomized control design, the experimental group $(n=7)$ received standardized patient verbal feedback and written rubric assessment, whereas the comparison group $(n=6)$ received written rubric assessment alone after completing standardized patient case scenarios. Outcome measures included the Modified Standardized Patient Satisfaction Questionnaire (MSPSQ), Professional Behaviors Assessment (PBA), and Professionalism Physical Therapy Core Values Assessment (PPTCVA). Results: Data analysis included pre and post intervention comparisons of Modified Standardized Patient Satisfaction Questionnaire rubric assessment scores, Professional Behaviors Assessment scores, and Professionalism Physical Therapy Core Values Assessment scores. No statistically significant differences were found on these outcome measures, although trends for changes in performance were noted. Conclusions: Limited research exists on the impact of standardized patients' verbal feedback with the use of a standardized rubric on physical therapist student professional behavior. This pilot study did not provide significant evidence on the value of this educational strategy in development of professional behaviors in doctoral physical therapist students. Future research may be beneficial to examine differences in perceptions of professional behavior between standardized patients, students, and faculty.
\end{abstract}

Key Words: simulation, physical therapist students, standardized patients 


\section{INTRODUCTION}

Professional behavior expectations for physical therapist (PT) students are outlined in the American Physical Therapy Association's (APTA) Normative Model of Physical Therapist Professional Education and by the Commission on Accreditation in Physical Therapy Education (CAPTE).1,2 Physical therapy educational programs and faculty advocate varied methods of explicitly teaching professionalism in their Doctor of Physical Therapy (DPT) curriculum to meet these expectations, including reflective classroom activities, small group discussions, role playing, and provision of feedback. . $^{3-5}$ In a qualitative study by Hayes, clinical instructors $(\mathrm{Cls})$ were asked to identify the behaviors that led them to question the competency of a PT student. ${ }^{6}$ Of these behaviors, $56.7 \%$ were considered to be lapses in the affective domain, with $29.1 \%$ related to unprofessional behavior and $27.6 \%$ related to poor communication. ${ }^{6}$ Of particular interest, students with cognitive deficits in basic knowledge were found to be 4.75 times more likely to receive feedback from Cls as compared to those with unprofessional behavior or poor communication. ${ }^{6}$ Explicit means of teaching professional behavior are consistent with adult learning theory and may be necessary to facilitate growth in students. ${ }^{7}$ Evidence demonstrates that PT students prefer learning professional behaviors through explicit, direct, and immediate feedback. ${ }^{8-11}$

Standardized patients (SPs) have also been used in varied medical fields, including physical therapy, to provide feedback on professional behavior during standardized case scenarios. Standardized patients are defined as "simulated... or actual patients... who have been trained to depict a patient case in a standardized manner."12 (page 443) Standardized patients have been used for the learning of professional behaviors in physical therapy. In an early study on interpersonal and communication skill development, PT students were videotaped interviewing a SP while being rated on their performance by peers and academic faculty. ${ }^{13}$ Overall, the peer assessments were significantly higher than the instructor ratings. ${ }^{13}$ These findings indicate peers may have overestimated interpersonal and communication skills, which questions the accuracy of such feedback.

In 2006, a model development study described the implementation of a novel method of using SPs in a community of practice (COP). ${ }^{14}$ Groups of 4 to 5 students created an assessment plan with faculty guidance on how to approach an assigned SP case with one single student who interviewed the SP. In the COP, students received feedback from multiple sources in a case study format. In subsequent research in 2010, Hayward and Blackmer expanded upon this model by incorporating the Professionalism in Physical Therapy Core Values Assessment (PPTCVA) as a self-assessment tool before and after a SP scenario, as well as after an 8-week clinical experience..$^{15}$ Hayward and Blackmer found an increase in PPTCVA scores after the SP scenario, which subsequently decreased after the clinical experience..$^{15}$ The decrease in scores after the clinical experience was only statistically significant for 2 items on the PPTCVA: altruism and social responsibility. Hayward and Blackmer suggested that the change in PPTCVA scores might reflect that students were more realistic in their self-assessments after the clinical experience. ${ }^{15}$

More recently, Blackstock et al and Watson et al completed separate randomized control trials examining 2 SP models using acute care or musculoskeletal cases, respectively.16,17 Both Blackstock et al and Watson et al used 2 models with the students either completing SP experiences for 1 week prior to a 4-week clinical experience, or completing interspersed SP experiences with clinical time for 2 weeks followed by a 2-week clinical experience. In the Blackstock et al study, there was a statistically significant difference in the professional behavior category favoring the group with the interspersed model in an acute care setting as measured by the Assessment of Physiotherapy Practice (APP)..$^{16}$ There was no statistically significant difference in the professional behavior standard of the APP between experimental groups in the study by Watson et al conducted in a musculoskeletal setting. ${ }^{17}$

Given that the APTA and CAPTE embrace professionalism for both PTs and PT students, the impact of SP feedback on student professional behavior is important to examine. There is limited research on the impact of SP feedback on student learning of professional behaviors, with written rubrics used as the most common form of feedback. ${ }^{16-18}$ The purpose of this study, therefore, was to compare professional behavior outcomes between PT students who received written rubric feedback alone and those who received both written rubric and verbal feedback from a SP.

\section{METHODS}

Subjects were recruited from a sample of convenience of 44 second-year PT students at a private university in the Northeast United States. The investigators did not have any prior established relationship with students in the recruitment pool. Inclusion criteria required subjects to be PT students who had no prior experiences with SPs and had not yet completed a full-time clinical experience. All subjects who volunteered met the inclusion criteria. Standardized patients were recruited by an expert SP educator. The Institutional Review Board from the involved institution approved this study. 
An experimental design was used with randomization of subjects into an experimental group (verbal feedback group) or comparison group (no verbal feedback group) using random, blinded numbers drawn from an envelope (Figure 1) Baseline and demographic data was collected after randomization including age, gender, APTA membership status, a history of receiving prior academic awards/scholarships, Professional Behaviors Abilities (PBA) scores, and PPTCVA scores. ${ }^{19,20}$

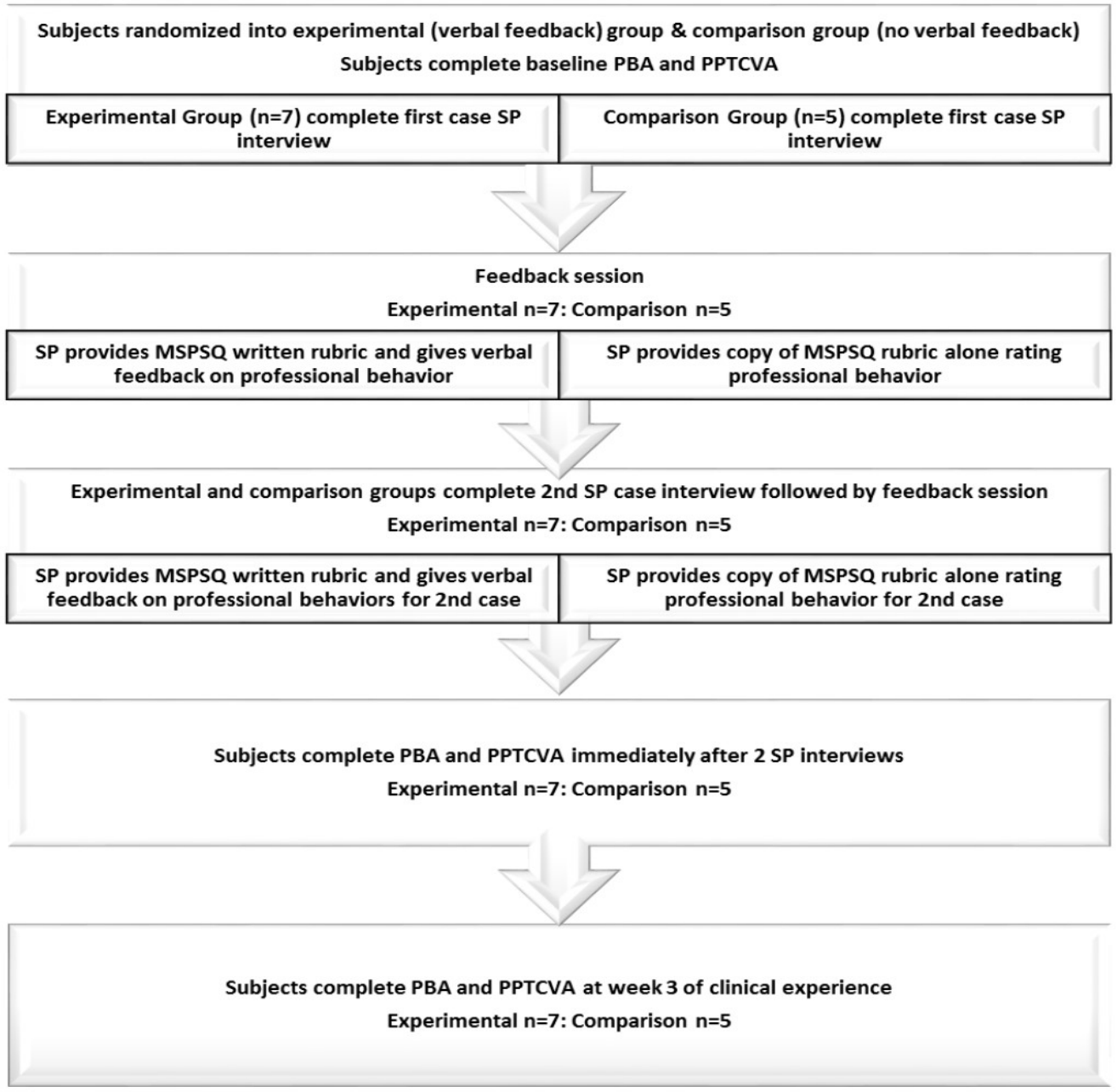

Figure 1: Randomization of Subjects

The primary investigator developed 2 standardized case scenarios with the assistance of both a content expert in clinical simulation and an experienced SP educator. The cases were developed to portray individuals with musculoskeletal disorders presenting to an outpatient clinical setting. Each case included SP responses designed to challenge the subject's professional behaviors (Appendices 1 and 2). The 2 standardized cases were conducted in random order for all subjects using identical cases for both the experimental and comparison groups.

An expert SP educator conducted a training session for all the SPs one week prior to the interviews including reviewing the case scenarios, role playing the cases, and providing feedback on the SP performance. The SPs were trained as a group to improve the consistency of instruction. They were educated on how to reliably and accurately portray the standardized cases to the subjects, and how to provide unbiased verbal feedback to subjects in the experimental group using the Modified Standardized Patient Satisfaction Questionnaire (MSPSQ). All SPs had been trained in a prior study on the MSPSQ and were proficient in its use..$^{21}$ 
Subjects were instructed to complete a medical history interview of a SP within a 15-20 minute time frame and were provided 10 minutes to review the case prior to the interview. Each subject was asked to complete only a medical history and was instructed to refrain from completing a physical examination during the encounters. Subjects were unaware that their professional behavior was being assessed. Two SP case scenarios were completed back to back by each subject in private rooms within a physical therapy clinic located on the academic campus. No attempt was made to track the quality of feedback provided by the SPS.

\section{Outcome Measures}

The MSPSQ consists of 14 professional behavior items that were rated by the SP on a Likert-type scale ranging from 1 to 5 , with 1 being poor and 5 being excellent (Appendix 3). The scores for each item were added to obtain an aggregate score. In prior research, the average consistency using an ICC model for the aggregate scores of the MSPSQ was .88, suggesting good reliability. ${ }^{21}$ The original Generic Abilities Assessment, now known as the PBA, includes an ordinal level rating scale that ranks self-efficacy in 10 domains of professional behavior. ${ }^{19,20}$ These domains include commitment to learning, interpersonal skills, communication, effective use of time and resources, use of constructive feedback, problem solving, professionalism, responsibility, critical thinking, and stress management. ${ }^{19}$ In the original Generic Abilities study, a scale was utilized by students and $\mathrm{Cls}$ to rate each individual domain on a scale from beginning to developing to advanced levels. ${ }^{19}$ In unpublished research in 2009, this scale was further expanded to describe 4 primary levels of increasingly complex performance as students improved their professional behaviors. This updated scale includes ratings from beginner to developing to entry-level and to post entrylevel, with clear operational definitions to improve the consistency of responses. ${ }^{20}$

The construct validity of the original Generic Abilities Assessment was examined by Jette and Portney using a factor analysis of 152 specific professional behaviors performed by students in a clinic environment.22 The findings suggested that the behaviors identified as most important by students were consistent with those of the Generic Abilities Assessment. ${ }^{22}$ Although the validity of the PBA has not been formally studied, the identical professional behaviors as established in the Generic Abilities are included, suggesting similar content validity. The intrarater reliability and responsiveness to change of the PBA have not been established.

In 2002, a group of experts in physical therapy practice, education, and research developed the PPTCVA, which is a description of core values or professional behaviors that are inherent components of physical therapy practice. ${ }^{23}$ In addition, the authors developed a self-assessment tool including operationalized sample indicators to be used by PTs to rate themselves on these behaviors. The PPTCVA includes a 5-point Likert-type scale that the subjects use to self-assess the frequency of the application of each professional core value. The rating scale frequencies include 1=never; 2=rarely; 3=occasionally; 4=frequently; and $5=$ always. ${ }^{23}$

Although the PPTCVA is not formally validated, it has been used as a self-assessment tool in prior physical therapy literature and is commonly used in educational practice. ${ }^{15,24,25}$ The PPTCVA contains 68 ordinal scale items grouped under general categories or domains. These domains include accountability, altruism, excellence, caring/compassion, social responsibility, integrity, and professional duty. In this current study, aggregate scores were calculated by adding the individual item scores in each domain. This approach was utilized to avoid potential overestimation of treatment effect from multiple comparisons of the 68 individual items. This approach is consistent with the intent of the scale in categorizing similar items into broad domains and has been utilized in prior research. ${ }^{15}$

\section{Data Collection}

Subjects in the experimental group received both verbal and written feedback from the SP via the MSPSQ (Appendix 3) immediately following each SP interview. Subjects in the comparison group received only written feedback from the SP, using the MSPSQ, after each respective case scenario. Upon completion of both scenarios, all subjects immediately completed the PBA and PPTCVA (post SP feedback) and at one additional time point at the end of the third week of a subsequent 8 to 10-week clinical experience. All subjects began their first full-time clinical experience within 6 to 12 weeks following the SP experiences. The PPTCVA and the PBA responses were collected using a password-protected computer program and concealed subject numbers. All outcome measures, with the exception of the MSPSQ, were collected electronically using Qualtrics@ survey software..$^{26}$ The SPs completed the MSPSQ in writing.

\section{Data Reduction and Data Analysis}

One subject who was allocated to the comparison group dropped out after randomization and did not complete the SP case scenarios. One subject had missing data on 1 item on the MSPSQ and was excluded from the analysis of aggregate MSPSQ scores. Non-parametric statistics were used based upon the ordinal level of data and small sample size. To measure central tendency and dispersion of the data, medians and interquartile ranges were calculated. 
For the MSPSQ, change scores were computed by subtracting the scores in the first case from the second case. These change scores were analyzed with a Mann-Whitney U Test $(\alpha=.05)$ to assess for differences between the groups on MSPSQ score between case scenarios. For the PBA and PPTCVA, change scores for each domain were calculated at 3 time points (baseline, immediately post SP scenario, and at the end of week 3 of the clinical experience), and comparisons were made using a Kruskal-Wallis ANOVA to examine for between-group differences. Bonferroni corrections were utilized to account for multiple comparisons in Kruskal-Wallis ANOVA post-hoc analyses $(a=.005)$. The statistical software SPSS $\odot$ Version 22 was used for all data analyses..$^{27}$

\section{RESULTS}

Thirteen second-year students, out of the potential sample of 44 PT students, volunteered to participate, met the inclusion criteria for the study, and were randomized to the experimental and comparison groups. There were no significant demographic differences between groups (Table 1). There were also no statistically significant differences between the experimental and comparison groups on the PBA or PPTVCA scores at baseline, except for the commitment to learning item on the PBA (Tables 2 and 3).

Table 1. Descriptive Data

\begin{tabular}{|l|c|c|c|}
\hline Characteristics & Experimental $(n=7)$ & Comparison $(n=6)$ & $\begin{array}{l}\text { p value (Mann- } \\
\text { Whitney U) }\end{array}$ \\
\hline Women, $n(\%)$ & $6(85.7)$ & $3(50.0)$ & .181 \\
\hline Age in years, median (IQR) & $24.0(3.0)$ & $23.0(2.0)$ & .545 \\
\hline APTA member, $n(\%)$ & $4(57.1)$ & $2(33.3)$ & .534 \\
\hline Prior awards/scholarships (\%) & $7(100)$ & $5(83.3)$ & .628 \\
\hline Grade point average, median (IQR) & $3.67(0.3)$ & $3.65(0.3)$ & .945 \\
\hline
\end{tabular}

Table 2. Professional Behaviors Assessment Scores at Baseline, median (IQR)

\begin{tabular}{|l|c|c|c|}
\hline & Experimental $(n=7)$ & Comparison $(n=6)$ & $\begin{array}{l}\text { p value (Mann- } \\
\text { Whitney U) }\end{array}$ \\
\hline Critical Thinking & $2.0(1.0)$ & $2.0(1.0)$ & .213 \\
\hline Communication & $2.0(0.0)$ & $2.5(2.0)$ & .793 \\
\hline Constructive Feedback & $2.0(0.0)$ & $2.0(1.0)$ & 1.00 \\
\hline Commitment to Learning & $2.0(1.0)$ & $2.0(1.0)$ & $.033^{*}$ \\
\hline Interpersonal Skills & $2.0(1.0)$ & $2.0(0.0)$ & .561 \\
\hline Problem Solving & $2.0(0.0)$ & $2.0(0.0)$ & .859 \\
\hline Problem Solving & $2.0(0.0)$ & $2.0(1.0)$ & .335 \\
\hline Responsibility & $2.0(0.0)$ & $2.0(0.0)$ & .280 \\
\hline Stress Management & $2.0(1.0)$ & $2.0(2.0)$ & .221 \\
\hline Use of Time and Resources & $2.0(1.0)$ & $2.0(1.0)$ & .335 \\
\hline
\end{tabular}

Note: $\mathrm{a}=.05$ 
Table 3. Professionalism Physical Therapy Core Values at Baseline, median (IQR)

\begin{tabular}{|l|c|c|c|}
\hline & Experimental $(n=7)$ & Comparison $(n=6)$ & $\begin{array}{l}\text { p value (Mann- } \\
\text { Whitney U) }\end{array}$ \\
\hline Accountability & $41.0(2.0)$ & $38.5(6.0)$ & .565 \\
\hline Altruism & $20.0(4.0)$ & $21.0(7.0)$ & .348 \\
\hline Compassion & $44.0(6.0)$ & $51.0(15.0)$ & .616 \\
\hline Excellence & $40.0(9.0)$ & $44.5(10.8)$ & .063 \\
\hline Integrity & $48.0(5.0)$ & $50.0(12.0)$ & .473 \\
\hline Professional Duty & $28.0(3.0)$ & $30.5(5.0)$ & .716 \\
\hline Social Responsibility & $39.0(16.0)$ & $38.0(10.0)$ & .512 \\
\hline
\end{tabular}

Note: $\alpha=.05$

Modified Standardized Patient Satisfaction Questionnaire Results

When analyzing the aggregate MSPSQ data between groups, there were no significant differences between the experimental and comparison groups on either case (Table 4).

Table 4. MSPSQ Descriptive Data, median (IQR)

\begin{tabular}{|l|c|c|c|}
\hline & Experimental $(n=6)$ & Comparison $(n=5)$ & $p$ value (Mann-Whitney U) \\
\hline Case 1 Aggregate Scores & $66.0(11.0)$ & $57.0(23.0)$ & .272 \\
\hline Case 2 Aggregate Scores & $64.5(11.0)$ & $64.0(9.0)$ & .522 \\
\hline
\end{tabular}

Note: $\mathrm{a}=.05$

\section{Professional Behaviors Assessment Results}

Baseline PBA item scores were compared to scores completed immediately after the SP case scenarios and at the end of week 3 of the clinical experience (Table 5). There was a trend toward significance on the item of problem solving and on the item for stress management. When examining the trends for problem solving and stress management, the difference was noted between the time frames of post SP PBA measures as compared to clinical experience measures. The experimental group tended to rate themselves equally high, whereas the comparison group tended to rate themselves lower on the problem solving and stress management domains.

Table 5. Professional Behaviors Assessment Results (Kruskal-Wallis ANOVA)

\begin{tabular}{|l|l|l|l|l|l|l|}
\hline & $\begin{array}{l}\text { Post SP } \\
\text { Experimental } \\
\text { Median (IQR)n } \\
=6\end{array}$ & $\begin{array}{l}\text { Post SP } \\
\text { Comparison } \\
\text { Median (IQR) } \\
\mathrm{n}=5\end{array}$ & $\begin{array}{l}\text { Baseline to } \\
\text { Post SP }(\mathrm{p} \\
\text { value })\end{array}$ & $\begin{array}{l}\text { CE } \\
\text { Experimental } \\
\text { Median (IQR) } \\
\mathrm{n}=6\end{array}$ & $\begin{array}{l}\text { CE } \\
\text { Comparison } \\
\text { Median (IQR) } \\
\mathrm{n}=5\end{array}$ & $\begin{array}{l}\text { Post SP to CE } \\
\text { ( } \mathrm{p} \text { value) }\end{array}$ \\
\hline Critical Thinking & $2.0(2.0)$ & $2.0(1.0)$ & .681 & $2.0(2.0)$ & $2.0(1.0)$ & .647 \\
\hline Communication & $2.0(1.0)$ & $2.5(1.0)$ & .681 & $3.0(1.0)$ & $2.5(1.0)$ & .244 \\
\hline $\begin{array}{l}\text { Constructive } \\
\text { Feedback }\end{array}$ & $2.0(1.0)$ & $2.5(1.0)$ & .633 & $3.0(1.0)$ & $2.0(1.0)$ & .171 \\
\hline $\begin{array}{l}\text { Commitment to } \\
\text { Learning }\end{array}$ & $2.0(2.0)$ & $2.0(1.0)$ & .619 & $2.0(2.0)$ & $2.0(1.0)$ & .361 \\
\hline
\end{tabular}




\begin{tabular}{|l|c|c|c|c|c|c|}
\hline $\begin{array}{l}\text { Interpersonal } \\
\text { Skills }\end{array}$ & $2.0(1.0)$ & $3.0(1.0)$ & .649 & $3.0(1.0)$ & $2.5(1.0)$ & .409 \\
\hline Problem Solving & $2.0(1.0)$ & $2.5(1.0)$ & .335 & $2.0(0.0)$ & $2.0(0.0)$ & .027 \\
\hline Professionalism & $2.0(1.0)$ & $2.5(1.0)$ & .499 & $3.0(1.0)$ & $3.0(1.0)$ & .058 \\
\hline Responsibility & $2.0(1.0)$ & $2.0(0.0)$ & .681 & $2.0(1.0)$ & $2.0(1.0)$ & .938 \\
\hline $\begin{array}{l}\text { Stress } \\
\text { Management }\end{array}$ & $2.0(0.0)$ & $3.0(2.0)$ & .805 & $2.0(1.0)$ & $2.0(1.0)$ & .036 \\
\hline $\begin{array}{l}\text { Use of Time and } \\
\text { Resources }\end{array}$ & $1.0(1.0)$ & $2.0(0.0)$ & .165 & $2.0(1.0)$ & $2.0(0.0)$ & .100 \\
\hline
\end{tabular}

\section{Professionalism in PT Core Values Assessment Results}

There were no significant differences on any domain of the PPTCVA between groups (Table 6). The item of excellence approached significance between groups from the baseline PPTCVA measure to the post SP PPTCVA measure.

Table 6. Aggregate Professionalism Physical Therapy Core Values Assessment Results (Kruskal-Wallis ANOVA)

\begin{tabular}{|l|l|l|l|l|l|l|}
\hline & $\begin{array}{l}\text { Post SP } \\
\text { Experimental } \\
\text { Median (IQR) } \\
\mathrm{n}=6\end{array}$ & $\begin{array}{l}\text { Post SP } \\
\text { Comparison } \\
\text { Median (IQR) } \\
\mathrm{n}=5\end{array}$ & $\begin{array}{l}\text { Baseline to } \\
\text { Post SP }(\mathrm{p} \\
\text { value) }\end{array}$ & $\begin{array}{l}\text { CE } \\
\text { Experimental } \\
\text { Median (IQR) } \\
\mathrm{n}=6\end{array}$ & $\begin{array}{l}\text { CE } \\
\text { Comparison } \\
\text { Median (IQR) } \\
\mathrm{n}=5\end{array}$ & $\begin{array}{l}\text { Post SP to CE } \\
\text { (p value) }\end{array}$ \\
\hline Accountability & $42.0(3.0)$ & $39.5(5.0)$ & .128 & $41.0(3.0)$ & $43.0(3.0)$ & .021 \\
\hline Altruism & $20.0(3.0)$ & $21.0(5.0)$ & .934 & $21.0(3.0)$ & $20.0(4.0)$ & .162 \\
\hline Compassion & $50.0(8.0)$ & $47.0(10.0)$ & .254 & $48.0(6.0)$ & $50.0(7.0)$ & .328 \\
\hline Excellence & $44.0(6.0)$ & $43.5(15.8)$ & .045 & $43.0(5.0)$ & $47.0(5.8)$ & .280 \\
\hline Integrity & $54.0(9.0)$ & $55.0(8.0)$ & .615 & $54.0(11.0)$ & $55.5(10.0)$ & .943 \\
\hline $\begin{array}{l}\text { Professional } \\
\text { Duty }\end{array}$ & $32.0(3.0)$ & $32.5(4.0)$ & .564 & $31.0(4.0)$ & $31.0(4.0)$ & .665 \\
\hline $\begin{array}{l}\text { Social } \\
\text { Responsibility }\end{array}$ & $41.0(7.0)$ & $39.0(10.0)$ & .886 & $39.0(10.0)$ & $41.5(12.0)$ & .885 \\
\hline
\end{tabular}

$S P=$ Standardized Patient; $C E=$ Clinical Experience, $a=.005$

\section{DISCUSSION}

\section{Modified Standardized Patient Satisfaction Questionnaire Analysis}

When analyzing the aggregate MSPSQ data between groups, there were no significant differences between the experimental and comparison groups on either case. Considering the variability of the scores on the first case and the small sample size, it is plausible that a type II error may have occurred, and a true difference may have existed between the first and second case scores. Similarities to the results of this study can be found in the literature. In prior research by Schlengel et al., nursing students were exposed to either SP encounters or role play (RP) experiences prior to their clinical rotations. ${ }^{28}$ The students who worked with SPs received feedback on communication skills from SPs after the encounters, while the students who participated in RP received feedback from peers. In the Schlengel study, there was no statistically significant differences in communication scores between the SP and RP groups during a clinical experience, but patient ratings of students from both groups were generally positive. 
Similar findings in this study were noted with a lack of between-group differences in MSPSQ rubric scores based upon the type of feedback experience provided to students. This finding aligns with Schlengel et al in that feedback scores were similar regardless of type of feedback provided. ${ }^{28}$ It should be noted that the study by Schlengel et al. study utilized patients who may have provided only positive feedback, which did not appear to be a factor in this current study. When one examines the scoring of the MSPSQ, there is significant variability in the scores suggesting that both positive and negative feedback was provided. This increased variability may have potentially resulted in an underestimation of effect.

In a pilot study completed by Becker et al, undergraduate nursing students were randomly assigned to a control group that completed written case studies in the classroom or an experimental group that participated in SP encounters. ${ }^{29}$ Based on SP overall ratings of interpersonal skills, there were no significant differences between subjects who completed the SP encounters versus the classroom cases studies. In the current study, there were also no differences in professional behavior ratings by SPS between the experimental and comparison groups as measured by the MSPSQ. In the Becker study, communication was the only domain measured using a written rubric. ${ }^{29}$ In this current study, more specific feedback was provided on multiple domains of professional behavior. The complexity of the domains of professional behavior may have impacted the ability to find a significant difference in the MSPSQ scores. Although there were similar findings on the use of a written rubric for feedback, this study and prior investigations had small sample sizes, therefore, strong conclusions on the effectiveness of different feedback experiences cannot be made.

\section{Professional Behaviors Assessment Analysis}

Although there was no statistically significant change on the PBA between groups, stress management and problem solving did show trends toward positive improvements when examining the time frame from the post SP experience to the mid clinical experience in the experimental group. In a study by Dearmon et al., lower anxiety levels were observed in nursing students exposed to SPs. ${ }^{30}$ These results support the findings in the current study, which found a trend toward improved confidence in favor of the experimental group when exploring a between-group comparison for stress management.

In a study by Rosenbraugh et al., faculty members rated medical student performance of problem solving during SP encounters. ${ }^{31} \mathrm{~A}$ correlation was found with later performance on examinations. ${ }^{31}$ These results suggest that problem solving may be positively influenced by participation in SP encounters. In the current study there was a trend toward improvement in the student's perceived problem-solving abilities after the SP encounters that continued into the clinical experience. These findings suggest that there may be differing levels of confidence in problem solving and stress management between the two groups once the subjects began their clinical experiences. This may be an important finding as the trend was an increase in ratings within the verbal feedback group in this current study.

\section{Professionalism PT Core Values Assessment Analysis}

In analysis of the PPTCVA data, there were no statistically significant differences between groups in any domains, except for excellence in the experimental group. The scores for excellence did increase from baseline to mid-clinical experience measure in the experimental group. There was a trend for an increase in the scores on the excellence domain once entering the clinical environment in the comparison group, but this did not approach significance. Prior evidence could not be identified that discussed student views on the impact of the patient perspective on physical therapy care and its relationship to developing excellence.

Research on the use of the PPTCVA as a tool to measure PT student self-assessments of professional behavior has shown that PPTCVA scores tend to increase when comparing an initial to a terminal clinical experience. ${ }^{24}$ Although this research does suggest that the PPTCVA shows change over time between clinical experiences, it is unknown if the PPTCVA is responsive to changes that occur before and after a first-time clinical experience. It may be postulated that the responsiveness of the PPTCVA may not be sufficient to identify small, yet relevant changes in self-assessed professional behavior.

The core value of accountability trended toward significance between groups when comparing the post SP to mid clinical experience measures. It is unclear as to why the difference in accountability occurred between the groups, however this is consistent with prior research in which student self-ratings of core values decreased after clinical experiences. ${ }^{15}$ Student selfratings of accountability may potentially change when exposed to an actual clinical setting.

The Core Values may be more relevant to practicing clinicians as compared to students despite being included in the Normative Model of Physical Therapist Professional Education. ${ }^{1}$ Students may not be sufficiently exposed to all of the domains of the 
PPTCVA during their education, especially early in the curriculum. The frequencies of reported behaviors by students may be lower simply based on lack of exposure. Literature could not be identified that addressed this concern.

\section{Limitations}

The use of a single DPT cohort from one physical therapy educational program and the small sample size may limit the external validity of the study and thus the generalizability to other students. A large percentage of the sample reported a history of awards or scholarships, as well as a relatively high average GPA. These characteristics need to be considered when generalizing results to other student populations. It cannot be discounted that individuals with lower GPAs or academic status may respond differently when provided with SP feedback.

The PT students completed their clinical experiences in diverse clinical settings in both the United States and internationallybased sites. One cannot discount the impact of factors such as patients with differing socioeconomic status, cultural customs, health literacy, language, and health care access on professional behaviors. In addition to the clinical setting, one should consider that the subjects were supervised by different Cls during their clinical experiences. Furthermore, the subjects in this study were exposed to two clinical scenarios that involved SPs in the outpatient setting, so it is unknown if the results are generalizable to other settings.

Threats to internal validity, including selection bias, were minimized by randomization during the assignment process. History and maturation cannot be discounted during the data collection of the PBA and the PPTCVA, based upon the time elapsed between collection points. One must also consider that changes may have occurred in PBA or PPTCVA scores during student clinical experiences unrelated to the SP experiences. This was minimized using a comparison group. Testing effects are possible with the PBA and PPTCVA, since these measures were completed at three time points. This effect was minimized by allowing sufficient time between repeated administrations so that subjects would be less likely to remember prior answers. Another potential limitation regarding outcome measures is that the PPTCVA is not formally validated. Finally, other limitations may include the use of self-reported data, as well as possible variation in SP feedback.

\section{CONCLUSIONS}

The approach of utilizing different forms of feedback was developed as a way of studying the effectiveness of SP feedback experiences as an instructional method. Directed SP feedback on multiple domains of professional behaviors was a novel approach as compared to prior studies that have concentrated solely on communication skills. Although the results of this pilot study were not significant, subjects who received both verbal and written feedback trended to rated themselves higher on the domains of excellence, problem solving, accountability, and stress management as compared to those who received only written feedback. These trends could have important educational implications in favor of the use of verbal SP feedback following SP case scenarios. Future research may be beneficial to examine differences in perceptions of professional behavior between SPs, students, and faculty. 


\section{REFERENCES}

1. American Physical Therapy Association. A Normative Model of Physical Therapist Education. 2004. Available at: http://www.apta.org. Accessed June 2, 2017.

2. Commission on Accreditation in Physical Therapy Education. Available at: http://www.capteonline.org. Accessed June 2, 2017.

3. Davis D. Teaching professionalism: a survey of physical therapy educators. J Allied Health. 2009;2:74-80. [PMID: 19623788]

4. Plack M, Santasier A. Reflective practice: a model for facilitating critical thinking skills within an integrative case study classroom experience. J Phys Ther Educ. 2004;18(1):4-12.

5. Williams R, Wessel J. Reflective journal writing to obtain student feedback about their learning during the study of chronic musculoskeletal conditions. J Allied Health. 2004;33(1):17-23. [PMID: 15053216]

6. Hayes KW, Huber G, Rogers J, Sanders B. Behaviors that cause clinical instructors to question the clinical competence of physical therapist students. Phys Ther. 1999;79:653-67. [PMID: 10416575]

7. Goulet C, Owen-Smith P. Cognitive-affective learning in physical therapy education: from implicit to explicit. J Phys Ther Educ. 2005;19(3):67-72.

8. Jarski RW, Kulig K, Olson RE. Clinical teaching in physical therapy: student and teacher perceptions. Phys Ther. 1990;70:173-8. [PMID: 2304975]

9. Lindquist I, Engardt M, Richardson B. Early learning experiences valued by physiotherapy students. Health Soc Care Community. 2004;3(1):17-25.

10. Cole B, Wessel J. How clinical instructors can enhance the learning experience of physical therapy in an introductory clinical placement. Adv in Health Sci Educ. 2008;13:163-79. [PMID: 17120080]

11. Milanese S, Gordon S, Pellatt A. Undergraduate physiotherapy student perceptions of teaching and learning activities associated with clinical education. Phys Ther Rev. 2013;18(6):439-44.

12. Barrows HS. An overview of the uses of standardized patients for teaching and evaluating clinical skills. Acad Med. 1993;68(6):443-51. [PMID: 8507309]

13. Ladyshewsky R, Gotjamanos E. Communication skill development in health professional education: the use of standardised patients in combination with a peer assessment strategy. In: Abbott J, Willcoxson L, eds. Teaching and Learning Within and Across Disciplines: Murdoch University; 1996:93-7. [PMID: 9451588]

14. Hayward LM, Blackmer B, Markowski A. Standardized patients and communities of practice: a realistic strategy for intergrating the core values in a physical therapist education program. J Phys Ther Educ. 2006;20(2):29-37.

15. Hayward LM, Blackmer B. A model for teaching and assessing core values development in doctor of physical therapy students. J Phys Ther Educ. 2010;24(3):16-26.

16. Blackstock F, Watson KM, Morris NR, Jones A, Wright A, et al. Simulation can contribute a part of cardiorespiratory physiotherapy clinical education: two randomized trials. Sim Healthcare. 2013;8(32-42):32-42. [PMID: 23250189]

17. Watson $\mathrm{K}$, Wright A, Morris N, McMeeken J, Rivett D, et al. Can simulation replace part of clinical time? two parallel randomised controlled trials. Med Educ. 2012;46:657-67. [PMID: 226463319]

18. Ladyshewsky R, Baker R, Jones M, Nelson L. Evaluating clinical performance in physical therapy with simulated patients. J Phys Ther Educ. 2000;14(1):31-7.

19. May WW, Morgan BJ, Lemke JC, Karst GM, Stone HL. Model for ability-based assessment in physical therapy education. J Phys Ther Educ. 1995;9(1):3-6.

20. May W, Kontney L, Iglarsh A. Professional Behaviors for the 21st Century. 2009. Available at: http://www.marquette.edu/physical-therapy/documents/ProfessionalBehaviors.pdf. Accessed June 2, 2017.

21. Riopel MA, Litwin B, Fernandez-Fernandez A, Silberman N. Inter-rater Reliability of the Modified Standardized Patient Satisfaction Questionnaire for Rating Professional Behaviors of Student Physical Therapists. American Physical Therapy Association Combined Section Meeting; 2015; Anaheim CA.

22. Jette D, Portney LG. Construct validation of a model for professional behavior in physical therapist students. Phys Ther. 2003;83(5):432-43. [PMID: 12718709]

23. Professionalism in Physical Therapy: Core Values. Available at: http://www.apta.org/Policies/CoreDocuments/. Accessed June 2, 2017.

24. Anderson D, Irwin KE. Self-assessment of professionalism in physical therapy education. Work. 2013;44:275-81. [PMID: 23324679]

25. Guenther L, McGinnis P, Romen M, Patel K. Self assessment of professional core values among physical therapists. HPA PTJ-PAL . 2014;14(2):1-10.

26. Qualtrics Online Survey Software. Available at: www.qualtrics.com. Accessed June 1, 2017. 
27. Statistical Package for the Social Sciences (SPSS), Version 22. Available at: http://www01.ibm.com/software/analytics/spss/. Accessed June 16, 2017.

28. Schlengel C, Woermann U, Shaha M, Rethans J, van der Vleuten. Effects of communication training on real practice performance: a role play module versus a standardized patient module. J Nur Educ. 2011;51(1):16-22. [PMID: 22085207]

29. Becker K, Rose LE, Berg JB, Park H, Shatzer JH. The teaching effectiveness of standardized patients. J Nur Educ. 2006;45(4):103-11. [PMID: 16629278]

30. Dearmon V, Graves RJ, Hayden S, Mulekar MS, Lawrence SM, et al. Effectiveness of simulation-based orientation of baccalaureate nursing students preparing for their first clinical experience. J Nur Educ. 2013;52(1):29-38. [PMID: 23230885]

31. Rosenbraugh C, Speer AJ, Ainsworth MA, Solomon DJ, Callaway MR, et al. Developing a presentation and problem solving station in a multistation standardized patient examination. Acad Med. 1996;71(1):S102-4. [PMID: 8546763] 
Appendix 1 (Standardized Patient Case A)

Brief case description:

The patient is a 60-year old man or woman coming for an initial physical therapy examination at an outpatient clinic. The patient twisted their right ankle 3 weeks ago while walking in grass in their yard. Patient has been in an Aircast and now has a referral from the orthopedist for physical therapy to address the stiffness, weakness, and pain in the injured ankle.

Standardized patient presentation:

Patient affect:

- Patient uses lay language, appropriate to college-educated person not working in the medical field.

- Patient is anxious and mildly frustrated, as he/she did not anticipate the residual deficits that would persist after using the Aircast.

- Patient is annoyed to be answering medical questions again.

- Patient is anxious about physical therapy in general.

Complaints:

"I twisted my ankle while walking on the grass."

Pain levels and description - If asked to rate pain, patient reports right ankle pain rated $6 / 10$ when walking and $3 / 10$ at rest.

Patient describes pain as dull over outside ankle.

Positive findings:

- Right ankle stiffness and right ankle weakness - "My right ankle feels a bit stiff and weak"

- Right ankle pain - located on outside of ankle - "My ankle does hurt especially with walking"

- Impaired standing and walking balance- "Feel a little off balance at times but do not fall"

\section{Communication/counseling challenges:}

Challenge question, following 5 minutes of interview: "I am sorry but I feel like I keep answering the same questions. The doctor already asked me this."

Challenge question following 10 minutes of interview "My friend told me that physical therapy can make it hurt worse. What exactly are you going to do?" 


\section{Appendix 2 (Standardized Patient Case B)}

\section{Brief case description:}

The patient is a 55-year old man or woman coming for an initial physical therapy examination at an outpatient clinic. The patient reports thigh pain which began 4 weeks ago. Patient does not report an injury and now has a referral from the orthopedist for physical therapy to address back pain. Patient also has a history of type 2 diabetes and depression.

Standardized patient presentation:

Patient affect:

- Patient language: lay language, appropriate to high school educated person not working in the medical field

- Patient's reaction to events: patient is mildly depressed and he/she does not understand why his/her thighs hurt. Patient is somewhat motivated, but expresses that he/she does not know what to expect from physical therapy and does not understand what is wrong with his/her legs.

- Patient responds readily to questions related to legs but responds with mild impatience to questions about back and may comment that his/her back does not hurt.

Patient complaints:

"I started having thigh pain 1 month ago. I have no idea why"

Pain - If asked to rate pain, patient reports constant thigh pain ranging from 6-8/10. Pain is throbbing and in located in the front of both thighs.

Positive findings: Thigh pain, weakness in legs

- "Legs feel slightly weak and I have pain in my thighs"

\section{Communication/counseling challenges:}

Challenge question, following 5 minutes of interview: "I don't understand why you are asking these questions about my back. I have pain in my legs"

Challenge question after 10 minutes of interview, "I am sorry but this is taking a long time. The doctor told me that I just needed some massage from the physical therapist." 
Appendix 3 (Modified Standardized Patient Satisfaction Questionnaire)21

$$
5=\text { excellent } \quad 4=\text { very good } \quad 3=\text { good } \quad 2=\text { fair } \quad 1=\text { poor }
$$

\begin{tabular}{|c|c|}
\hline Being up-front and candid to the patient. & $\begin{array}{llll}1 & 2 & 3 & 4 \\
\end{array}$ \\
\hline Introducing themselves; greeting the patient warmly; being friendly, never rude. & $\begin{array}{llll}1 & 2 & 3 & 4 \\
\end{array}$ \\
\hline Maintaining eye contact and demonstrating respectful body language. & 12 \\
\hline Treating the patient like they are on the same level, never talking down to the patient. & 12 \\
\hline $\begin{array}{l}\text { 5. Letting the patient tell their story; listening carefully, not interrupting the patient while they are } \\
\text { talking. }\end{array}$ & 12 \\
\hline $\begin{array}{l}\text { 6. Showing interest in the patient as a person; asking thoughtful questions; not acting bored or } \\
\text { ignoring what the patient has to say. }\end{array}$ & 12 \\
\hline Discussing options with the patient, asking the patient's opinion, and offering choices. & 34 \\
\hline $\begin{array}{l}\text { 8. Encouraging the patient to ask questions, answering patient questions clearly, never avoiding } \\
\text { patient questions or lecturing them. }\end{array}$ & 12 \\
\hline $\begin{array}{l}\text { 9. Explaining the specifics of the patient's problems-how and why they occurred and what to } \\
\text { expect next. }\end{array}$ & 12 \\
\hline $\begin{array}{l}\text { 10. Using words the patient can understand when explaining their problems and treatment, } \\
\text { explaining any technical medical terms in plain language. }\end{array}$ & 12 \\
\hline $\begin{array}{l}\text { 11. Acknowledging the patient's feelings about their problems and the impact of the patient's } \\
\text { problems on their life. }\end{array}$ & 12 \\
\hline 12. The interview flow made sense and the questions followed logically. & 12 \\
\hline 13. The student remained calm when the patient challenged him or her. & 12 \\
\hline 14. Thinking of the entire encounter, please rate the student on professional behavior. & 12 \\
\hline
\end{tabular}

